\title{
A simple route to functionalising electrospun polymer scaffolds with surface biomolecules
}

\author{
Karolina Dziemidowicz ${ }^{1}$, Steve Brocchini ${ }^{1}$, Gareth R. Williams ${ }^{1 *}$ \\ 1 UCL School of Pharmacy, University College London, 29-39 Brunswick Square, London WC1N 1AX, UK \\ * Author for correspondence. Email: g.williams@ucl.ac.uk; Tel: +44(0) 2077535863.
}

\section{Introduction}

Surface functionalisation of polymeric biomaterials is frequently explored in regenerative medicine and tissue engineering (Chen et al., 1997; Rim et al., 2013, 2012; Zhang et al., 2005), for applications such as wound healing (Chen et al., 2020) or presentation of antigens for $\mathrm{T}$ cell activation (Fadel et al., 2014). The ability to safely coat a polymeric surface with a protein without the loss of its functional activity is often critical in the successful targeted delivery of biomolecules.

15 Electrospinning is a material fabrication method in which a polymer solution is dispersed into a fine jet under the influence of an electric field, resulting in a formation of fibrous scaffolds. Such fibres can be loaded with therapeutic agents, from small molecules (Bukhary et al., 2020) to proteins (Moreira et al., 2020), for sustained and localised drug release. Moreover, the 3Dstructure of intertwined electrospun fibres provides a large area for further surface

20 functionalisation, making it an attractive substrate for the prolonged presentation of biologically active molecules (Dziemidowicz et al., 2021). Several bioconjugation methods suitable for the surface functionalisation of electrospun polymeric materials have been explored in the literature, with examples including mussel-inspired polydopamine chemistry (Liu et al., 2019), maleimide-sulfhydryl reactions (Bai and Liu, 2014) or carbodiimide-based crosslinkers (Guex et al., 2014).

Another approach, relatively unexplored in the literature, involves surface functionalisation using photo-assisted perfluorophenyl azide (PFPA) chemistry. Recently, Luetzow et al. 
(Luetzow et al., 2019) reported an effective method of electrospun polydioxanone fibre surface modification using PFPA with an N-hydroxysuccinimide (NHS) end group (PFPA-NHS). By adding the NHS group to the PFPA structure, any amine-containing molecule can in principle be covalently conjugated to a hydrocarbon-containing molecule via a stable covalent bond.

One possible application of such protein-functionalised biomaterials is the delivery of catalase in oncological photodynamic therapy (PDT). PDT involves the use of a photosensitiser capable of generating reactive oxygen species (ROS) upon excitation with visible or near infrared light (Li et al., 2019). A major limitation of this therapy is the hypoxic microenvironment within most solid tumours, which impedes the therapeutic efficacy of oxygen-dependent PDT (Cheng et al., 2020). Catalase, a natural enzyme capable of decomposing $\mathrm{H}_{2} \mathrm{O}_{2}$ to produce $\mathrm{O}_{2}$, has been applied for local inhibition of tumour hypoxia (Wang et al., 2018). When administered intravenously, however, it tends to be effectively cleared by proteases during blood circulation, which reduces the potency of its action. Localised delivery of catalase on the surface of implantable electrospun scaffolds could potentially overcome the problem.

Although preliminary studies have shown effective conjugation of model molecules to hydrocarbon-based surfaces using PFPA-NHS (Luetzow et al., 2019; Yan et al., 1994), little is known about the in vitro performance of such composites or the retention of protein functionality following grafting onto a polymeric surface. This study therefore aimed to explore the feasibility of PFPA-NHS functionalisation of electrospun poly( $\varepsilon$-caprolactone) (PCL) scaffolds for the delivery of catalase. An extensive physicochemical characterisation of the modified fibres was performed, together with an investigation of conjugation efficiency and screening for cytotoxicity in cell culture models. 


\section{Materials and methods}

\subsection{Materials}

2,2,2-trifluoroethanol (99.8\%), albumin-fluorescein isothiocyanate conjugate (FITC-BSA), catalase from bovine liver (2,000-5,000 units/mg protein), hydrogen peroxide solution (30\%), methyl pentafluorobenzoate (99\%), N-(3-Dimethylaminopropyl)-N'-ethylcarbodiimide hydrochloride (EDC· $\mathrm{HCl}), \mathrm{N}-\mathrm{Hydroxysuccinimide} \mathrm{(NHS),} \mathrm{poly(- \varepsilon -caprolactone)} \mathrm{(80} \mathrm{kDa),}$ potassium periodate, Purpald ${ }^{\circledR}$, sodium phosphate dibasic heptahydrate, sodium phosphate monobasic monohydrate were supplied by Sigma-Aldrich (UK). N-(6-Aminohexyl)rhodamine 6G-amide bis(trifluoroacetate) were purchased from Santa Cruz Biotechnology (UK) and

60 Bradford Ultra ${ }^{\mathrm{TM}}$ was supplied by Expedeon (UK).

\subsection{Methods}

\subsubsection{Synthesis of PFPA-NHS}

\subsubsection{Synthesis of methyl 4-azidotetrafluorobenzoate (B)}

The reaction was performed in the dark. Methyl pentafluorobenzoate (A) (10 mL, $15.3 \mathrm{~g}, 68$ $\mathrm{mmol})$ was dissolved in a 2:1 v/v mixture of acetone $(100 \mathrm{~mL})$ and deionized water $(50 \mathrm{~mL})$. Sodium azide $(5.75 \mathrm{~g}, 88.5 \mathrm{mmol})$ was added and the reaction mixture was stirred and heated under reflux for $5 \mathrm{~h}$. Afterwards, the reaction mixture was allowed to cool down to room temperature, diluted with water $(200 \mathrm{~mL})$ and extracted with ethyl acetate $(4 \times 100 \mathrm{~mL})$. The extract was washed with brine $(2 \times 100 \mathrm{~mL})$ and the organic phase was dried with magnesium

sulfate. Ethyl acetate was removed under reduced pressure by rotoevaporation to produce a yellowish solid (13.30 g, 87\%). ${ }^{1} \mathrm{H} \mathrm{NMR}\left(500 \mathrm{MHz}, \mathrm{CDCl}_{3}\right): \delta=3.97$ (s, $\left.3 \mathrm{H}, \mathrm{OCH}_{3}\right) \mathrm{ppm}$. ${ }^{13} \mathrm{C}$ NMR (500 MHz, $\left.\mathrm{CDCl}_{3}\right): \delta=160.0\left(\mathrm{~s}, \mathrm{CO}_{2} \mathrm{CH}_{3}\right), 146.6-139.5$ (qm, C-F), 123.5 (tt, $\left.\mathrm{CN}_{3}\right)$, $107.8\left(\mathrm{t}, \mathrm{CCO}_{2} \mathrm{CH}_{3}\right), 53.4\left(\mathrm{q}, \mathrm{OCH}_{3}\right) \mathrm{ppm}$.

\subsubsection{Synthesis of 4-azidotetrafluorobenzoic acid (C)}

75 The reaction was performed in the dark. Methyl 4-azidotetrafluorobenzoate (13.30 g, 56.6 mmol) (B) was dissolved in methanol $(75 \mathrm{~mL})$ and aqueous sodium hydroxide $(5 \mathrm{M}, 10 \mathrm{~mL})$ was added. After 5 hours of stirring more methanol $(35 \mathrm{~mL})$ and aqueous sodium hydroxide 
$(5 \mathrm{M}, 2 \mathrm{~mL})$ were added. After 24 hours, the reaction mixture was diluted with water $(15 \mathrm{~mL})$ and acidified with aqueous $1 \mathrm{M}$ hydrochloric acid in a dropwise manner under constant stirring until the solution reached $\mathrm{pH}=1$. The reaction mixture was then diluted with water $(100 \mathrm{~mL})$ and extracted with dichloromethane $(4 \times 100 \mathrm{~mL})$. The extract was washed with brine $(2 \times 100$ $\mathrm{mL}$ ) and the organic phase was dried with magnesium sulfate. The solvent was removed under reduced pressure by rotoevaporation to produce a yellowish solid (C) $(10.37 \mathrm{~g}, 78 \%) .{ }^{13} \mathrm{C}$ NMR (500 MHz, DMSO-d $): \delta=164.3\left(\mathrm{~s}, \mathrm{CO}_{2} \mathrm{H}\right), 146.6-139.5$ (qm, C-F), 122.7 (s, CN $\left.\mathrm{CN}_{3}\right), 108.4$ (s, $\left.\mathrm{CCO}_{2} \mathrm{H}\right) \mathrm{ppm}$.

\subsubsection{Synthesis of PFPA-NHS (D)}

The reaction was performed in the dark. A mixture of (C) (3.2 g, $13.6 \mathrm{mmol}), \mathrm{EDC} \cdot \mathrm{HCl}(3.1$ $\mathrm{g}, 16.2 \mathrm{mmol})$ and NHS (1.85 g, $16.1 \mathrm{mmol})$ was dissolved in dichloromethane $(70 \mathrm{~mL})$ and allowed to react at $35^{\circ} \mathrm{C}$ for 24 hours under constant stirring. Additional $\mathrm{EDC} \cdot \mathrm{HCl}(1.62 \mathrm{~g}, 8.6$

mmol) was added to the reaction mixture and stirring continued for a further 24 hours. The reaction mixture was diluted with water $(60 \mathrm{~mL})$ and extracted with dichloromethane $(3 \times 100$ $\mathrm{mL})$. The extract was washed with brine $(2 \times 100 \mathrm{~mL})$ and the organic phase was dried with magnesium sulfate. The solvent was removed under reduced pressure by rotoevaporation to produce a beige solid. The obtained product was purified by precipitation into ice-cold 2propanol to produce PFPA-NHS (D) as a white solid (2.65 g, 83\%). ${ }^{1} \mathrm{H}$ NMR (500 MHz, $\left.\mathrm{CDCl}_{3}\right): \delta=2.90\left(\mathrm{~s}, 4 \mathrm{H}, \mathrm{COCH}_{2}\right) \mathrm{ppm} .{ }^{13} \mathrm{C} \mathrm{NMR}\left(500 \mathrm{MHz}, \mathrm{CDCl}_{3}\right): \delta=168.4\left(\mathrm{~s}, \mathrm{COCH}_{2}\right)$, 155.3 (t, $\mathrm{CO}_{2} \mathrm{~N}$ ), 146.6-139.5 (qm, C-F), 126.5 (s, CN 3 ), 102.1 (t, $\left.\mathrm{CCO}_{2} \mathrm{~N}\right), 25.8$ (t, $\left.\mathrm{CH}_{2}\right)$ ppm. IR: $v=2995,2955(\mathrm{C}-\mathrm{H}), 2120\left(\mathrm{~N}_{3}\right), 1775,1735,1705,1640(\mathrm{C}=\mathrm{O}), 1480(\mathrm{C}=\mathrm{C}), 1410$, $1360,1250,1205,1135,1065,990 \mathrm{~cm}^{-1}$.

\subsubsection{Nuclear magnetic resonance (NMR)}

${ }^{1} \mathrm{H}$ NMR and ${ }^{13} \mathrm{C}$ NMR were performed using a Bruker Avance $500 \mathrm{MHz}$ spectrometer equipped with a helium-cooled multinuclear cryoprobe. The Larmor frequency was $500.13 \mathrm{MHz}$ for ${ }^{1} \mathrm{H}$ NMR and $125.76 \mathrm{MHz}$ for ${ }^{13} \mathrm{C}$ NMR. The results were analysed with the TopSpin 4.0.5 software.

\subsubsection{Preparation of electrospun PCL fibres}


105 Fibres were prepared by electrospinning a solution of $12 \%$ w/v PCL (Mw 80 kDa) in 2,2,2trifluoroethanol (TFE). The solution was carefully loaded into $5 \mathrm{~mL}$ disposable plastic syringes and dispensed through a $21 \mathrm{G}$ stainless steel needle (Nordson EFD, UK) connected to a highvoltage direct-current power supply (15 kV; HCP 35-35000, FuG Elektronik, Germany) at a flow rate of $1.8 \mathrm{~mL} / \mathrm{h}$ (controlled by a 78-9100C syringe pump (Cole Parmer, UK)). The fibres

110 were collected on aluminium foil placed on top of a $14.7 \mathrm{~cm} \times 20 \mathrm{~cm}$ metal plate collector connected to the grounded electrode. The distance from the needle to the collector was $16 \mathrm{~cm}$. The experiments were conducted at $25 \pm 2{ }^{\circ} \mathrm{C}$ and relative humidity $35 \pm 10 \%$.

\subsubsection{PFPA-NHS functionalisation of electrospun PCL fibres}

A solution of PFPA-NHS $(20 \mathrm{mg} / \mathrm{mL}$ in methanol, $10 \mu \mathrm{L})$ was pipetted onto the surface of a 115 square cut from a PCL fibre mat $(0.5 \mathrm{~cm} \times 0.5 \mathrm{~cm})$ and subsequently dried under reduced pressure (in a desiccator) to remove solvent. Afterwards, the fibre mats were placed under a UV lamp (8-watt, $254 \mathrm{~nm}, 50 \mathrm{~Hz}$ ) and irradiated from a distance of $10 \mathrm{~cm}$. The length of exposure needed to achieve functionalisation was experimentally determined by monitoring the reaction using Fourier transform infrared spectroscopy (FTIR). Control samples of

120 untreated and PFPA-NHS-treated but non-irradiated fibres were included in experiments. Following functionalisation, the scaffolds were briefly immersed in methanol to remove unbound PFPA-NHS and dried under reduced pressure. The fibres were washed twice with sterile phosphate buffered saline (PBS) before incubation with proteins.

\subsubsection{Morphological and physicochemical characterisation}

\subsubsection{Scanning electron microscopy}

A sample of approximately $0.5 \mathrm{~cm} \times 0.5 \mathrm{~cm}$ was cut from each fibre mat, mounted onto an aluminium stub (TAAB Laboratories, UK) with carbon-coated adhesive tabs, and sputtercoated with $20 \mathrm{~nm}$ gold for 5 minutes (Q150R coater, Quorum, UK) in an argon atmosphere. Analysis was performed with a cerium hexaboride thermionic filament scanning electron

130 microscope (Phenom Pro, Thermo, Netherlands) connected to a secondary electron detector. The size of the fibres was calculated using ImageJ software version 1.52a (National Institutes 
of Health, USA) with a minimum sample size of 100, from three SEM images. The size distribution curves were prepared using Prism software version 8.4.2 (GraphPad, USA).

\subsubsection{Fourier transform infrared spectroscopy}

135 FTIR spectra of samples (cut to approximately $0.2 \mathrm{~cm} \times 0.2 \mathrm{~cm}$ ) were obtained using a Spectrum 100 spectrometer (Perkin Elmer, USA). The spectral data were analysed with the Prism software version 8.4.2 (GraphPad, USA). Data were collected over the wavenumber range from $650-4000 \mathrm{~cm}^{-1}$, with resolution $1 \mathrm{~cm}^{-1}$ and 4 scans obtained per sample.

\subsubsection{X-ray photoelectron spectroscopy (XPS)}

140 X-ray photoelectron spectroscopy (XPS) of samples (approximately $0.2 \mathrm{~cm} \times 0.2 \mathrm{~cm}$ ) was performed using a Thermo Scientific K-alpha spectrometer (ThermoFisher Scientific, UK) equipped with a $180^{\circ}$ hemispherical analyser and an aluminium K-alpha micro-focused monochromator $(1486.68 \mathrm{eV})$, with a $100 \mathrm{~W}$ power source. Measurements were performed in constant analyser energy mode. Pass energy was set to 50-200 eV, base pressure in the analysis

145 chamber below $2 \times 10^{-8} \mathrm{~Pa}$, and energy step size to $0.1 \mathrm{eV}$. Total scan numbers of 15 and 30 were used for survey and high-resolution scans respectively. C1s, O1s, N1s, and F1s peak areas from high-resolution elemental surface spectra were quantified and corrected for atomic sensitivity using the Thermo Avantage v.5 software (ThermoFisher Scientific, UK) or CasaXPS version 2.3.16 (Casa Software Ltd, UK). Prism software version 8.4.2 (GraphPad, 150 USA) was used to plot survey spectra.

\subsubsection{Conjugation of fluorescently-labelled model molecules}

N-(6-aminohexyl)rhodamine 6G-amide bis(trifluoroacetate) (termed "rhodamine-amine") was dissolved in methanol $(5 \mathrm{mg} / \mathrm{mL})$. Albumin-fluorescein isothiocyanate conjugate (termed 'FITC-BSA') was diluted with PBS $(20 \mu \mathrm{g} / \mathrm{mL})$. A small piece of a PFPA-NHS-functionalized electrospun PCL fibre mat $(0.5 \mathrm{~cm} \times 0.5 \mathrm{~cm})$ was immersed in the dye solution of either rhodamine-amine or FITC-BSA overnight at room temperature. After thorough washing with PBS to remove the unbound dye, the fibres were dried and viewed under an inverted fluorescence microscope (EVOS XL Cell Imaging System digital inverted microscope, ThermoFisher Scientific, UK). 


\subsubsection{Preliminary albumin attachment study}

Functionalised fibres cut to $1 \times 1 \mathrm{~cm}$ pieces were placed in a 12-well plate. Each well was then filled with $1 \mathrm{~mL}$ of bovine serum albumin (BSA) solution $(40 \mu \mathrm{g} / \mathrm{mL}$ in PBS). The fibres were incubated in the protein solution for 1, 3, 6, 8, 11 and 24 hours. At each time point, the fibre mat was taken out of the well and washed with PBS. The protein concentration in the incubation and washing solutions was measured using a Bradford protein assay. $150 \mu \mathrm{L}$ of sample and $150 \mu \mathrm{L}$ of Bradford ULTRA ${ }^{\mathrm{TM}}$ reagent (Expedeon, UK) were added to a 96 well plate and the plate was mixed thoroughly on a plate shaker at $100 \mathrm{rpm}$ for $30 \mathrm{~s}$. The absorbance was read at $595 \mathrm{~nm}$ using a SpectraMax M2e microplate reader (Molecular Devices, UK).

The amount of protein was calculated by multiplying concentration by the initial BSA solution volume (1 mL). The percentage protein attachment was calculated using Equation (1).

$$
\% \text { attachment }=\frac{\text { amount }_{0}-\text { amount }_{x}}{\text { amount }_{0}} \times 100 \%
$$

where amount $_{0}$ corresponds to the amount of protein at 0 hours (i.e. incubation solution; $~ 40$ $\mu \mathrm{g})$ and amount $_{x}$ is the amount of protein present at $x$ hours

\subsubsection{Cytotoxicity to Caco-2 cells}

The colorectal adenocarcinoma cell line Caco-2 (ATCC ${ }^{\circledR}$ HTB-37) was used to test the 175 cytotoxicity of the functionalised fibres. The cell culture was maintained at $37{ }^{\circ} \mathrm{C}$, under $5 \%$ $\mathrm{CO}_{2}$, in Dulbecco's modified Eagle medium (DMEM; Gibco ${ }^{\mathrm{TM}}$, UK) supplemented with penicillin-streptomycin solution $(1 \% \mathrm{v} / \mathrm{v})$ and $20 \% \mathrm{v} / \mathrm{v}$ heat-inactivated foetal bovine serum $\left(\right.$ Gibco $\left.^{\mathrm{TM}}, \mathrm{UK}\right)$. The culture was maintained between $8 \times 10^{4}$ and $1 \times 10^{5}$ viable cells $/ \mathrm{mL}$. For cytotoxicity studies, $150 \mu \mathrm{L}$ of cells at $5 \times 10^{4}$ cells $/ \mathrm{mL}$ were seeded in a flat-bottom 96 -well plate (Costar, UK) and incubated for 24 hours. Following PFPA-NHS-functionalisation as described in Section 2.2.3, the fibres were washed either by dipping in a methanol solution or by treating with two brief sonication steps. In step one, the scaffolds (cut to $0.5 \times 0.5 \mathrm{~cm}$ pieces) were placed in a glass vial with $15 \mathrm{~mL}$ of methanol and sonicated in an ultrasonic bath for one minute. In step two, the same procedure was followed, except methanol was replaced with 
sterile PBS. Subsequently, the fibres were gently removed with sterile tweezers, blotted with tissue paper to remove excess PBS from the surface under aseptic conditions, and introduced to the wells containing adhered cells using sterile tweezers. The plate was incubated for one or three days to measure cell viability. At the end of the incubation period, the fibres were removed, and cell viability was quantified using the PrestoBlue ${ }^{\mathrm{TM}}$ Cell Viability reagent. Each

190 experiment was performed three times on separate days, with three replicate wells per experiment.

\subsubsection{Catalase attachment study}

PFPA-NHS-functionalised and sonicated fibres cut to $0.5 \times 0.5 \mathrm{~cm}$ pieces were placed in a flatbottomed 96 -well plate and $200 \mu \mathrm{L}$ of a $25 \mu \mathrm{g} / \mathrm{mL}$ catalase (from bovine liver) solution in PBS

195 was added. The plate was then tightly sealed and placed on a plate shaker set to $500 \mathrm{rpm}$. After 11 hours at room temperature, the incubation solutions were collected and the fibres washed twice with PBS. The protein concentrations of the incubation and washing solutions were measured using the Bradford ULTRA ${ }^{\mathrm{TM}}$ assay and the total protein loading was calculated using Equation (1).

\subsubsection{Catalase activity assay}

The retention of catalase activity following grafting onto the fibre surface was assessed using an assay based on the previously published protocol (Johansson and Håkan Borg, 1988). Catalase-functionalised fibres $(0.5 \times 0.5 \mathrm{~cm})$ were prepared as outlined in Section 2.2.8 and placed at the bottom of a 96-well plate (one piece of fibre per well). The positive control comprised a freshly prepared catalase solution $(25 \mu \mathrm{g} / \mathrm{mL})$. For the negative control, the same catalase solution was heated at $95^{\circ} \mathrm{C}$ for $10 \mathrm{~min}$ to denature the enzyme.

To each well, $100 \mu \mathrm{L}$ of assay buffer (100 mM sodium phosphate buffer, $\mathrm{pH} 7.0), 30 \mu \mathrm{L}$ of methanol and $20 \mu \mathrm{L}$ of sample buffer ( $25 \mathrm{mM}$ sodium phosphate buffer, $1 \mathrm{mM}$ EDTA, $0.1 \%$ w/v BSA, pH 7.5) were added. The reaction was initiated by quickly adding $20 \mu \mathrm{L}$ of aqueous

$210 \mathrm{H}_{2} \mathrm{O}_{2}(35.28 \mathrm{mM})$ to all wells. Afterwards, the plate was covered and incubated for 20 minutes on a plate shaker $(100 \mathrm{rpm})$ at room temperature. Next, $30 \mu \mathrm{L}$ of $10 \mathrm{M} \mathrm{KOH}$ solution was added to terminate the reaction, followed by $30 \mu \mathrm{L}$ of Purpald ${ }^{\circledR}$ solution ( 25 mg of Purpald ${ }^{\circledR}$ in 
$4 \mathrm{~mL}$ of $480 \mathrm{mM} \mathrm{HCl}$ ). The plate was once again covered and incubated for 10 minutes on a plate shaker $(100 \mathrm{rpm})$ at room temperature. To stop the assay, $10 \mu \mathrm{L}$ of $\mathrm{KIO}_{4}\left(75 \mathrm{mg}\right.$ of $\mathrm{KIO}_{4}$ in $4 \mathrm{~mL}$ of $470 \mathrm{mM} \mathrm{KOH}$ ) was added to each well and the plate was incubated for another 5 minutes on a plate shaker $(100 \mathrm{rpm})$ at room temperature. Afterwards, the fibres were removed from the wells and $100 \mu \mathrm{L}$ of reaction mixture was transferred onto a clean 96-well plate to read absorbance at $540 \mathrm{~nm}$ using a SpectraMax M2e microplate reader (Molecular Devices, UK). Each formulation was tested in triplicate. The results are presented as optical density (OD) at $540 \mathrm{~nm}$.

\subsubsection{Catalase release assay}

PFPA-NHS-functionalised and sonicated fibres cut to $2 \times 2 \mathrm{~cm}$ pieces were placed in a flatbottomed 12-well plate and catalase in PBS $(1 \mathrm{mg} / \mathrm{mL}, 1 \mathrm{~mL})$ was added. The plate was then tightly sealed and incubated for 24 hours at room temperature under constant shaking (100 rpm). Afterwards, the fibres were removed from the wells using tweezers, washed with PBS (2 $\times 1 \mathrm{~mL}$ ) and placed in glass vials containing $5 \mathrm{~mL}$ of $\mathrm{PBS}$ at $37^{\circ} \mathrm{C}$ under constant shaking (100 $\mathrm{rpm})$. At pre-determined timepoints, $0.5 \mathrm{~mL}$ of supernatant was removed and replenished with fresh PBS. The protein concentrations of the incubation and washing solutions were measured using the Bradford ULTRA ${ }^{\mathrm{TM}}$ protein assay and the total amount of protein attached to the

230 fibre was calculated by depletion using Equation (1). Cumulative release of catalase was then calculated using Equation (2).

$$
\text { Cumulative release }(\%)=\frac{C_{x} \times V_{t}+\sum C_{x-1} \times V_{a}}{\text { Protein loading }} \times 100 \%
$$

where $C_{x}$ is the protein concentration in the release supernatant at time $x, V_{t}$ is the total volume of release media $(5 \mathrm{~mL}), V_{a}$ is the sampling volume $(0.5 \mathrm{~mL})$ and the Protein loading is the total amount of protein attached to the fibre. 


\section{Results and discussion}

This study explored the post-fabrication functionalisation of electrospun PCL fibres using PFPA-NHS to enable safe conjugation of catalase (Scheme 1). In this approach, plain PCL fibres are first produced using monoaxial electrospinning, and post-functionalised with PFPA-

NHS by immersion in methanolic solution of the compound, followed by thorough solvent removal under reduced pressure and subsequent photoactivation under UV lamp. The PFPANHS functionalised fibres can then undergo reaction with any amine-containing compounds (such as proteins) via the NHS moiety.

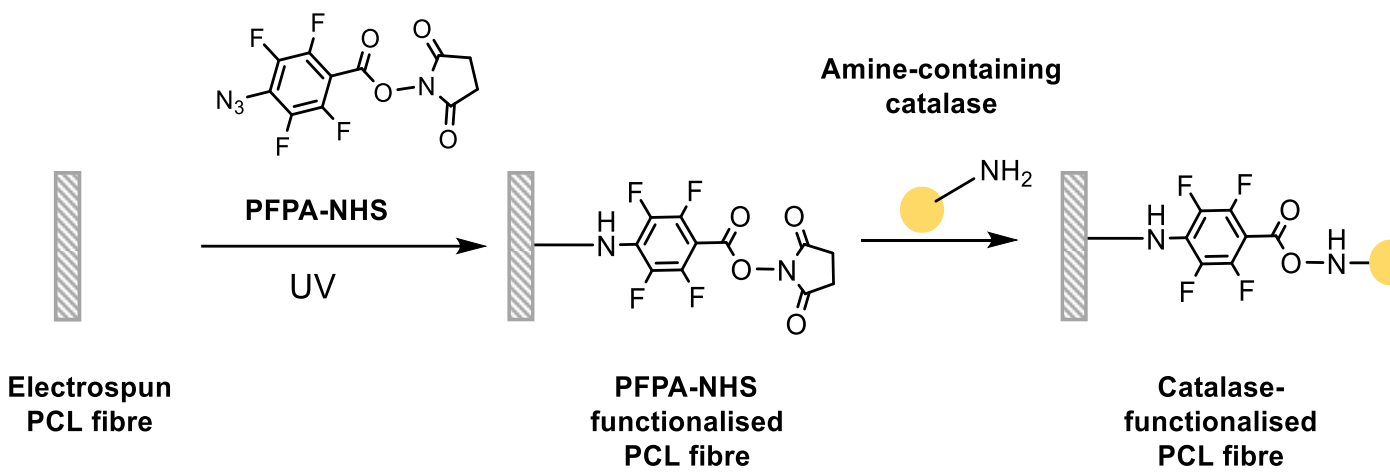

245 Scheme 1: A schematic of PCL fibre functionalisation using PFPA-NHS followed by protein conjugation.

\subsection{PFPA-NHS synthesis}

The three-step synthesis of PFPA-NHS was performed based on a previously published procedure (Scheme 1) (Luetzow et al., 2019).<smiles>COC(=O)c1c(F)c(F)c(F)c(F)c1F</smiles>

(A)

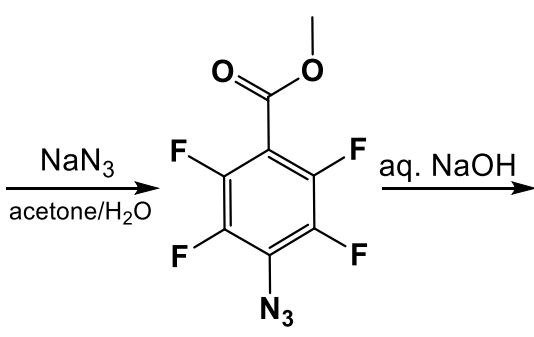

(B)<smiles>N#Cc1c(F)c(F)c(C(=O)O)c(F)c1F</smiles>

(C)<smiles>Nc1c(F)c(F)c(C(=O)ON2C(=O)CCC2=O)c(F)c1F</smiles>

(D)

Scheme 2: Synthesis of N-succinimidyl 4-azidotetrafluorobenzoate (PFPA-NHS).

The structure of the purified compound was investigated using $\mathrm{C}^{13}$ NMR (Supplementary Information, Figure S1) and FTIR (Figure S2). Both NMR and FTIR spectra are consistent 
with previously published data on PFPA-NHS (Luetzow et al., 2019; Yan et al., 1994) and confirm the successful synthesis of this compound.

\subsection{Fabrication of electrospun PCL fibres}

The successful formation of electrospun patches largely depends on the polymer and solvent selected for the fibre fabrication. PCL, a semi-crystalline polymer widely used in the manufacturing of surgical sutures, drug delivery systems and tissue engineering scaffolds, was selected for this study. It is biocompatible and biodegrades through hydrolysis over a time

260 period ranging from several months to years, depending on the molecular weight (Chiu et al., 2020; Labet and Thielemans, 2009), making it an attractive polymer for an implantable formulation. Moreover, it is not soluble in methanol or ethanol and can be safely functionalised with a methanolic PFPA-NHS solution and pre-sterilised in EtOH for biological applications. 2,2,2-trifluoroethanol (TFE) was selected as the solvent due to its well-described applications in nanofibre fabrication (Angkawinitwong et al., 2017; Cao et al., 2010; Zhang et al., 2005). A solution of $12 \% \mathrm{w} / \mathrm{v}$ PCL $(\mathrm{Mw} \sim 80 \mathrm{kDa})$ in TFE was previously found to have appropriate viscosity for the electrospinning process and thus chosen for use here (Angkawinitwong, 2018).

Scanning electron microscopy images of the scaffolds produced (Figure 1a and b) revealed successful fabrication of smooth, cylindrical fibres with no bead-on-string structures, suggesting appropriate optimisation of electrospinning conditions. The mean fibre size was found to be $709 \pm 366 \mathrm{~nm}$ (Figure 1c).
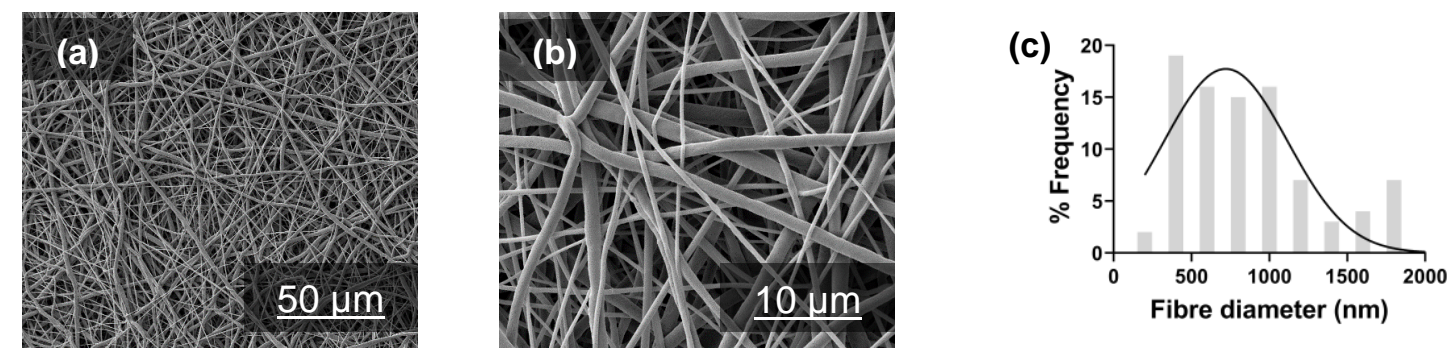

Figure 1: Scanning electron micrographs of electrospun PCL at two magnifications (a) 2000X; (b) 10 $000 \mathrm{X}$ and size distribution (c) of electrospun PCL fibres.

\subsection{Functionalisation of PCL fibres with PFPA-NHS}

275 Once the plain PCL scaffolds were produced, the post-fabrication functionalisation of electrospun PCL fibres using PFPA-NHS was explored. Physicochemical characterisation was 
performed to obtain information on the chemical composition of the modified PCL surface. The initial optimisation of PFPA-NHS conjugation reaction conditions was carried out by monitoring the FTIR spectra (Figure S3). After 30 minutes of UV radiation the reaction 280 appeared to be complete, as evidenced by the disappearance of the azide peak.

The effect of the functionalisation step on fibre morphology was then investigated with SEM (Figure S4). Figure S3a and b show the morphology of untreated fibres, with uniform cylindrical fibres present before surface manipulation. Dipping in methanol clearly does not affect the fibre morphology. Following incubation in PFPA-NHS solution (Figure S3c and d),

285 the fibres are slightly more irregular in shape and white deposits are visible in the higher magnification images, as highlighted by yellow arrows. PFPA-NHS and UV-treated fibres (Figure S3e and f) are visibly bundled and intertwined, with white clusters distributed evenly across the surface of the fibre. The white residue coating the fibres could be a precipitate of PFPA-NHS. The fibre patters are markedly less regular after UV treatment, suggesting that the 290 UV treatment negatively impacted the morphology of electrospun scaffolds.

As PFPA-NHS functionalisation on the surface of electrospun materials has been tried only once before (Luetzow et al., 2019) with PDO patches, little is known about its impact on the fibre morphology. The authors of the previous study did not include electron micrographs of the PDO nanofibres after the PFPA functionalisation (Luetzow et al., 2019). However, the

295 confocal microscope images they presented do show a rather distorted structure as compared to the SEM of PDO fibres before functionalisation. A similar observation was made here for PFPA-NHS-treated PCL fibres. Overall, it appears that the fibre mat remains intact after PFPA treatment, but the effect of the distorted surface on biological performance needs to be explored in further experiments.

300 XPS was used to further characterise the chemistry of the fibre surface. Since PFPA-NHS contains fluorine and nitrogen in its structure, these elements were chosen as diagnostic markers to corroborate successful surface functionalisation. Representative XPS survey spectra are presented in Figure S5. For untreated samples, the survey spectra identified elements corresponding to the PCL structure (carbon and oxygen) (Chiu et al., 2020), while in PFPA305 NHS-treated samples additional fluorine and nitrogen signals were detected. The XPS survey 
analysis allowed for the quantification of surface elements (Table S1). As expected, untreated PCL fibres contained no surface nitrogen or fluorine, while for the PFPA-NHS-functionalised fibres before and after UV treatment both elements could be detected. The percentage of nitrogen decreases after UV treatment, which indicates that photolysis of the azide group occurred. The percentage of nitrogen and fluorine present on the surface is relatively low compared to carbon and oxygen, which can be attributed to the polycaprolactone structure making up the bulk of the material. Similar observations were made in other studies where PFPA was conjugated to a polymer surface (Li et al., 2013; Luetzow et al., 2019; Zorn et al., 2014).

315 The C 1s high-resolution XPS spectra (Figure 2) show the changes in carbon environment following photografting onto the PCL surface. In untreated (Figure 2a) and PFPA-NHS-treated fibres before UV treatment (Figure 2b), peaks at $284.5(\mathrm{C}-\mathrm{H}), 286.2(\mathrm{C}-\mathrm{O}-\mathrm{C})$ and $288.5 \mathrm{eV}$ $(\mathrm{O}=\mathrm{C}-\mathrm{O})$ are characteristic of the PCL backbone. The peak detected for UV-treated samples (Figure 2c) was fitted into four components: $284.4(\mathrm{C}-\mathrm{H}), 286.1(\mathrm{C}=\mathrm{C}-\mathrm{N}$ and $\mathrm{C}-\mathrm{O}), 287.6$ $(\mathrm{C}=\mathrm{C}-\mathrm{F})$ and $288.8 \mathrm{eV}(\mathrm{O}=\mathrm{C}-\mathrm{O})$ (Zorn et al., 2014), confirming the structural change to the fibre surface.

(a)

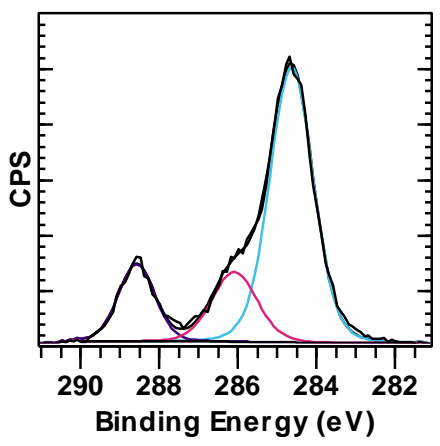

(b)

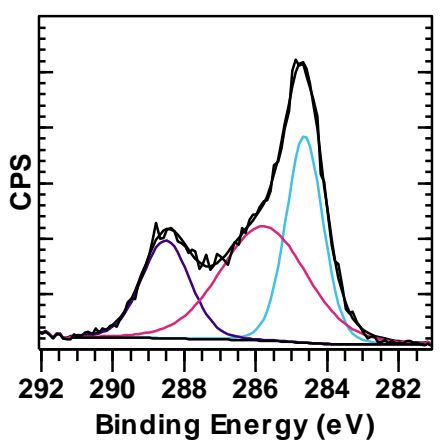

(c)

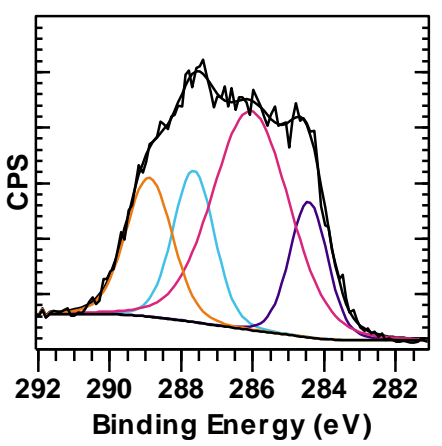

Figure 2: High resolution C1s XPS spectra for (a) untreated and PFPA-NHS-treated fibres before (b) and after (c) UV treatment. The peaks detected for UV-treated samples $(284.4(\mathrm{C}-\mathrm{H}), 286.1(\mathrm{C}=\mathrm{C}-\mathrm{N}$ and $\mathrm{C}-\mathrm{O}), 287.6(\mathrm{C}=\mathrm{C}-\mathrm{F})$ and $288.8 \mathrm{eV}(\mathrm{O}=\mathrm{C}-\mathrm{O}))$ confirm the structural change to the fibre surface.

325 High-resolution N1s XPS spectra (Figure 3) confirmed the covalent immobilisation of PFPA on the PCL fibre. No nitrogen signal was detected in untreated fibres (Figure 3a). In PFPANHS-treated samples before UV irradiation (Figure 3b), a prominent peak at $404.5 \mathrm{eV}$ can be assigned to the azide moiety (Zorn et al., 2014). After UV treatment (Figure 3c), the peak at 
404.5 eV disappears. This peak corresponds to the $\mathrm{N}^{+}$in the azide group of PFPA, which 330 decomposes upon photoactivation. The amine/amide species are visible at $401.5 \mathrm{eV}$ (Zorn et al., 2014) both before and after UV treatment. The results agree with the extensive XPS analysis of nitrogen species present on perfluorophenyl azide-functionalised surfaces performed by Zorn et al. (Zorn et al., 2014).

(a)

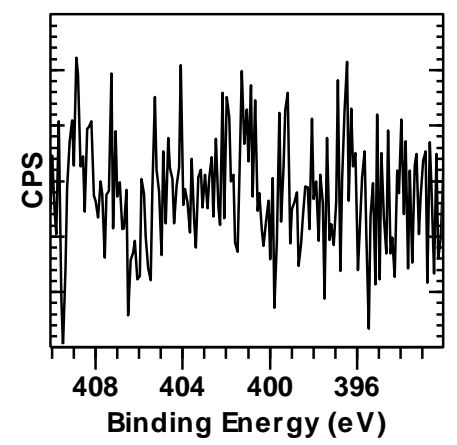

(b)

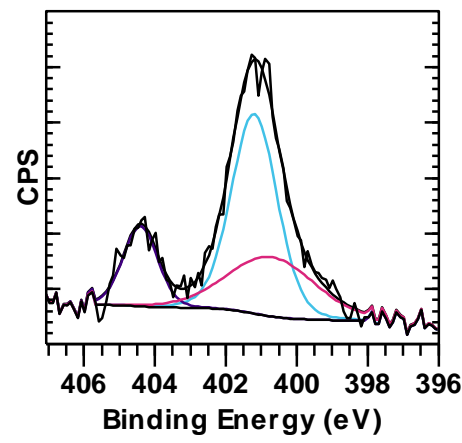

(c)

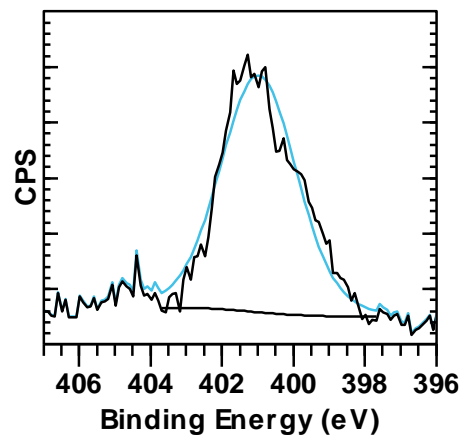

Figure 3: High resolution N1s XPS spectra for (a) untreated and PFPA-NHS-treated fibres before (b) and after (c) UV treatment.

Overall, physicochemical characterisation confirmed the successful deposition of PFPA-NHS on the surface of electrospun fibres.

\subsection{Model protein conjugation}

The functionality of the NHS ester group after immobilisation on the polymer fibre surface was explored using fluorescently-labelled model molecules (rhodamine-amine and FITC-BSA; see Figure 4). 

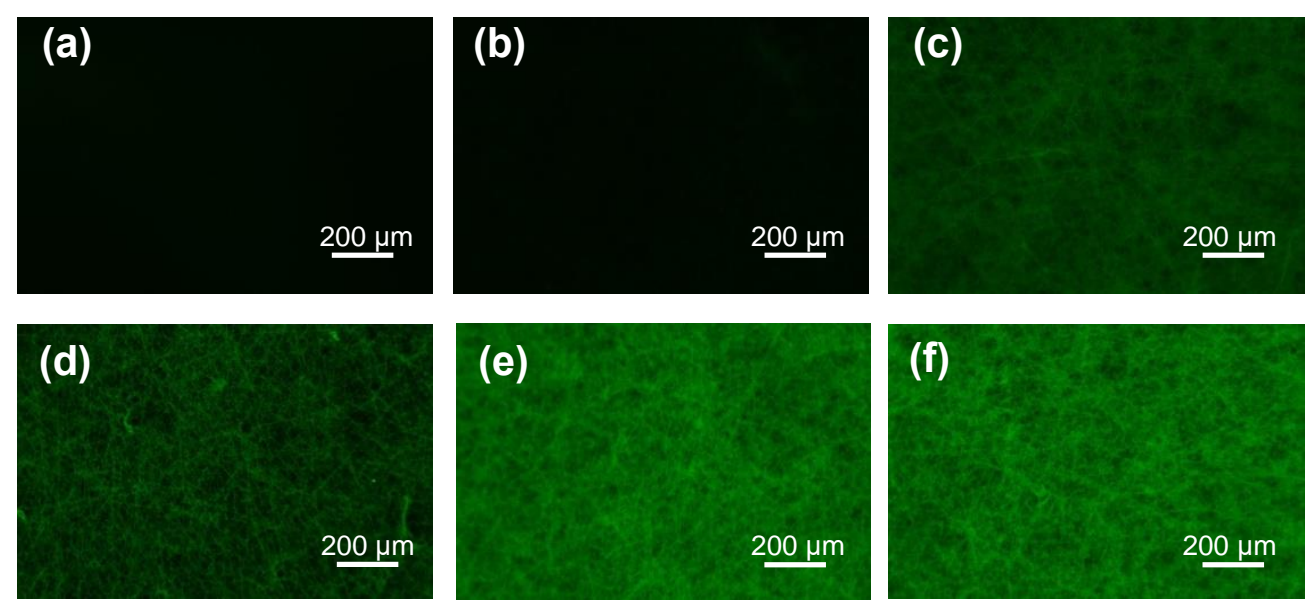

Figure 4: Conjugation of fluorescently-labelled model molecules to untreated electrospun fibres $(\mathrm{a}, \mathrm{d})$ and PFPA-NHS-treated fibres before UV (b,e) and after UV irradiation (c,f). Top row (a,b,c) shows the micrographs of rhodamine-amine treated samples, while bottom row $(\mathrm{d}, \mathrm{e}, \mathrm{f})$ presents fibres incubated with FITC-BSA.

Rhodamine-amine has been previously used to confirm the functionality of the PFPA-NHS moiety following grafting on electrospun PDO fibres (Luetzow et al., 2019). Following overnight incubation in a solution of rhodamine-amine dye, untreated (Figure 4a) and PFPANHS-treated fibres before UV exposure (Figure 4b) showed no fluorescence, while

350 the micrograph of the UV-irradiated sample (Figure 4c) revealed a homogenous distribution of the dye. On the other hand, FITC-BSA treated samples showed some level of fluorescence, with relatively lower intensity observed with blank fibres (Figure 4d) than in PFPA functionalised samples before and after UV treatment (Figure $4 \mathrm{e}$ and $\mathrm{f}$, respectively). This could be due to non-specific adsorption of BSA to the surface. Physical adsorption of proteins is driven by electrostatic, van der Waals and hydrophobic interactions (Dziemidowicz et al., 2021; Yoshida et al., 2006), and poorly wettable substrates have been linked to elevated surface protein adsorption (Ogueri et al., 2019). It is therefore possible that the hydrophobic BSA readily coated the hydrophobic surface of the PCL fibres. The fluorescence intensity of the PFPA-NHS-treated sample before and after UV treatment was comparable, suggesting that both formulations were loaded with similar levels of FITC-BSA.

To quantify the effect of PFPA-NHS functionalisation on the protein binding efficiency, a 24hour BSA attachment study was carried out (Figure S6). The fibres were incubated in the protein solution for $1,3,6,8,11$ and 24 hours and the percentage of BSA conjugation to the PCL fibres was calculated indirectly by depletion. At all measured time points the percentage 
attachment was higher for PFPA-NHS-treated samples compared to the untreated control. In PFPA-NHS-treated fibres, the conjugation efficiency increased gradually with time, reaching a maximum of around $80 \%$ at 11 hours. The results of the protein conjugation study (Figure S6) are consistent with the fluorescence imaging (Figure 4) described above, where the PFPANHS samples without UV treatment show a significant level of fluorescence intensity upon treatment with FITC-BSA.

\subsection{Cytotoxicity assays}

The cytotoxicity of PFPA-NHS-functionalised fibres was assessed using a model human epithelial cell line (Caco-2), measuring cell viability following incubation with fibres for one or three days (Figure S7). For the initial assays, after functionalisation washing was performed by dipping the functionalised fibres in methanol and PBS to remove unreacted PFPA-NHS. When these formulations were applied to Caco-2 cells, the cells retained their viability at around $100 \%$ after one day of incubation with the test formulations. However, PFPA-NHStreated fibres, both before and after UV irradiation, showed cytotoxic properties at day three of incubation, where viability decreased from $\sim 100 \%$ to $\sim 30 \%$. This could suggest that the washing method of briefly dipping the functionalised fibres in methanol to remove unreacted, physically absorbed PFPA-NHS may not be sufficient, resulting in a possibly toxic azide compound leaching out to the cell culture medium with longer incubation times.

To test this hypothesis, a more vigorous washing method comprising a two-step sonication process in an ultrasonic bath was employed. In step one, unreacted PFPA-NHS was removed via one-minute sonication in methanol. This step also pre-sterilises the fibres for cell culture use. In step two, the functionalised scaffolds were washed in sterile PBS to remove organic solvent that could be potentially dangerous for the integrity of the protein that will subsequently be attached to the surface. The results of cell viability experiments using the new washing protocol are given in Figure 5. Caco-2 cells retained their viability at around 100\% after both one and three days of incubation with the test formulations, demonstrating that after sonication washing the covalently-conjugated PFPA-NHS does not have a negative effect on cell viability. 


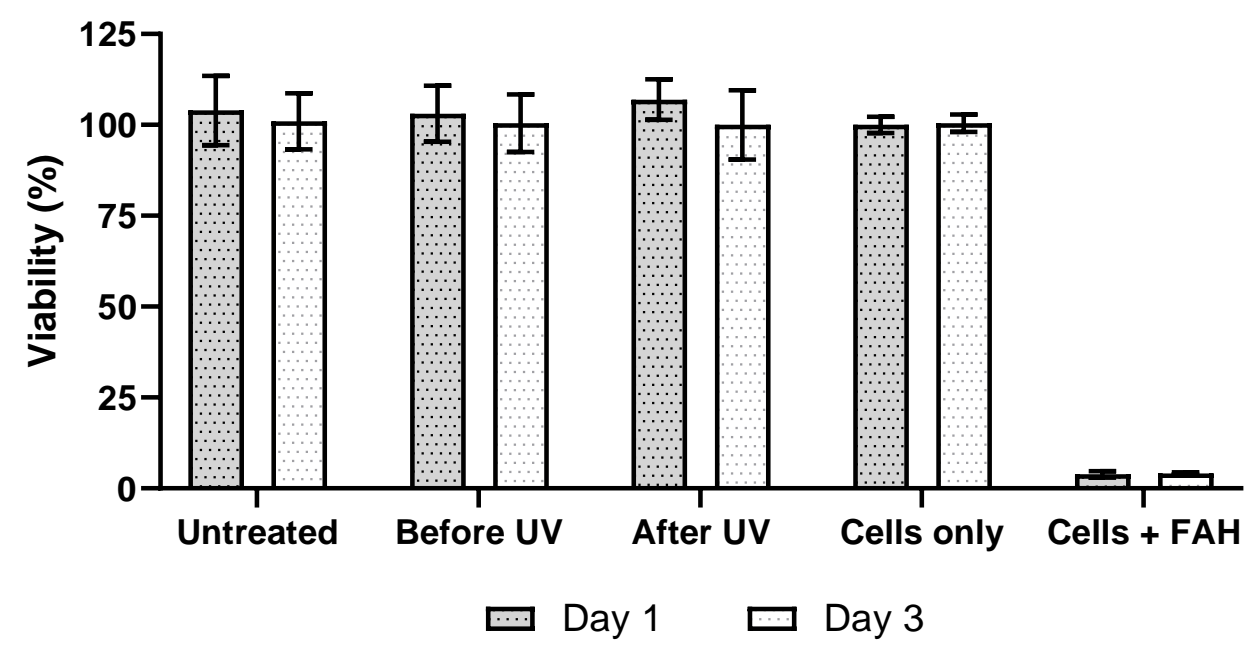

Figure 5: Viability of Caco-2 cells following incubation with sonicated PFPA-NHS-functionalised fibres for one (grey) and three (dashed) days. 'Untreated' refers to untreated (no PFPA-NHS) PCL fibres. Cells only are the negative control. Cells+FAH denotes the positive control (cells treated with formaldehyde). Data are shown as mean \pm S.D. and are representative of three independent experiments performed on separate days, with triplicate wells per each condition tested.

Sonication in an organic solvent (methanol), although brief (1 min), could potentially affect the morphology and surface chemistry of the electrospun fibres. To explore this, SEM was

400 performed (Figure S8). Compared to non-sonicated, dip-washed fibres, the morphology of the untreated fibres (Figure S8a) is slightly distorted after sonication, which could suggest that the sonication step introduced changes to the fibre morphology. The clusters observed in PFPANHS-treated samples in Figure S3c-f are no longer observed post-sonication, however (Figure $\mathrm{S} 8 \mathrm{~b}$ and $\mathrm{c})$. This observation, coupled with the substantial decrease in the nitrogen and fluorine surface percentage observed in the XPS survey spectra (Table S2), indicates that the introduction of the sonication washing step was necessary for the removal of excess PFPANHS from the fibre surface.

\subsection{Catalase attachment}

Once the biocompatibility of PFPA-NHS fibres was established in-vitro, the attachment of catalase on the PFPA-NHS-functionalised fibres was attempted (Figure 6). All tested conditions achieved at least $40 \%$ attachment following overnight incubation in a catalase solution for $11 \mathrm{~h}$ (based on the results of the BSA attachment study). The percentage protein loading on blank PCL fibres was significantly lower than in PFPA-NHS-functionalised patches before $(p<0.05)$ and after $(p \leq 0.01)$ UV treatment. PFPA-NHS-functionalised fibres before 
415 UV treatment performed slightly worse than those after UV exposure, but the observed difference was insignificant.

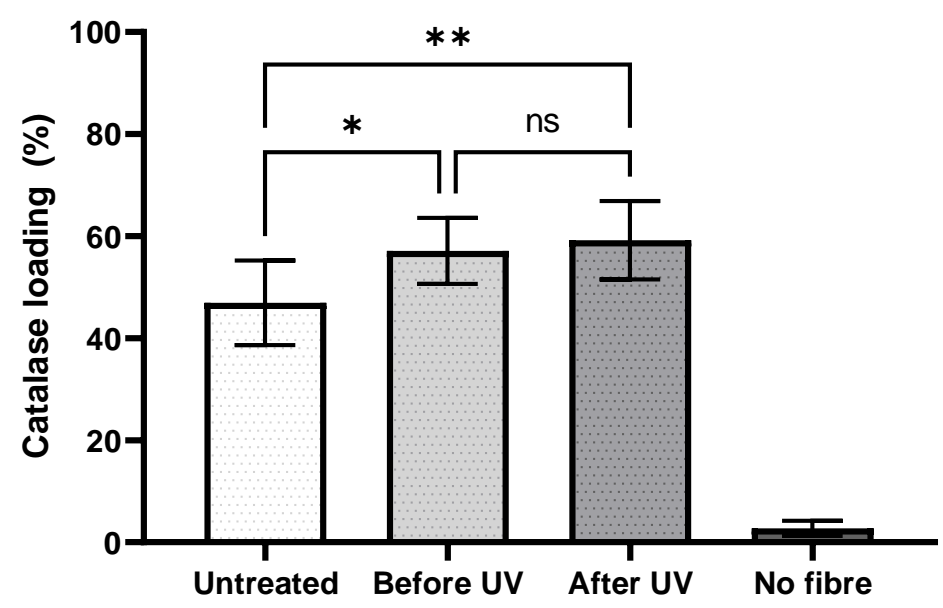

Figure 6: Attachment of catalase to PFPA-NHS-functionalised fibres following overnight incubation. Data are shown as mean \pm S.D. and are representative of three independent experiments performed on separate days, with triplicate wells per each condition tested. Repeated measures one-way ANOVA with post hoc Tukey's test; statistical significance: ns ( $p$-value $>0.05),{ }^{*}(p$-value $<0.05),{ }^{* *}(p$-value $\leq 0.01),{ }^{* * *}(p \leq 0.001){ }^{* * * *}(p-v a l u e \leq 0.0001)$.

\subsection{Catalase release}

425 Although the attachment of catalase was achieved in both untreated and PFPA-NHSfunctionalised fibres, it is expected that PFPA-NHS functionalisation results in a covalent conjugation of proteins to the fibre (rather than surface adsorption on the untreated fibres). This could potentially prevent rapid detachment of proteins upon exposure to physiological fluids, therefore extending the therapeutic efficacy of the scaffold at the implantation site. In the context of the proposed application, the prolonged presentation of catalase on a solid polymeric substrate could possibly avoid protease-mediated breakdown of the enzyme observed when the drug is administered intravenously. The release of catalase from the fibres was studied during incubation in PBS over six days (Figure 7). 


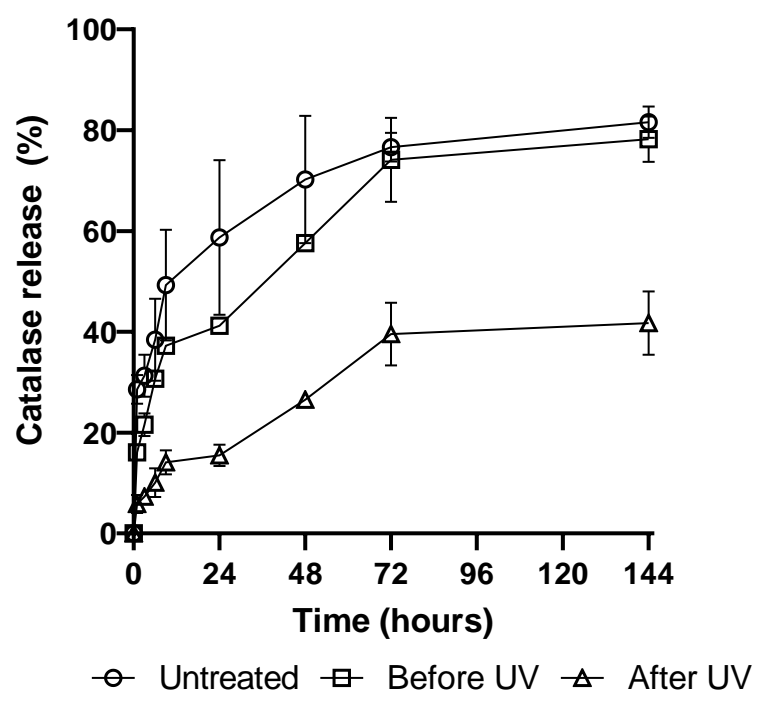

435 Figure 7: Catalase release profile over six days following incubation with untreated and PFPA-treated fibres before and after UV exposure. Data are shown as mean \pm S.D. $(n=3)$.

The release profiles confirm that PFPA-NHS functionalisation prolongs the presentation of catalase on the electrospun fibres. Within the first 24 hours, untreated and PFPA-NHS-treated fibres before UV exposure exhibited rapid release of catalase (60\% and 40\%, respectively).

440 PFPA-NHS-treated fibres after UV exposure did not follow this trend, with less than $20 \%$ of the protein loading being released after one day. After six days, the cumulative release reached $40 \%$ for photo-exposed PFPA-NHS-treated fibres, while both untreated and PFPA-NHStreated fibres before UV exposure showed $>70 \%$. It is evident that weak forces of physical adsorption were unable to retain catalase on the fibre surface in aqueous media under constant shaking. The data presented above clearly support the idea of using photo-activated PFPANHS on the surface of PCL fibres for prolonged presentation of proteins on the polymeric surface.

\subsection{Catalase activity post-functionalisation}

When designing protein delivery systems, it is important to recognise the potentially detrimental effect of the fabrication method on the biomolecule stability and structural activity. In the PFPA-NHS functionalisation approach, the fibres are only exposed to organic solvents in the initial PFPA-NHS functionalisation step before proteins are introduced on the surface. This should protect the protein from any accidental damage during the functionalisation 
procedure, which can be carried out in purely aqueous conditions. To test this hypothesis, the catalase activity was measured following attachment to the fibre surface (Figure 8).

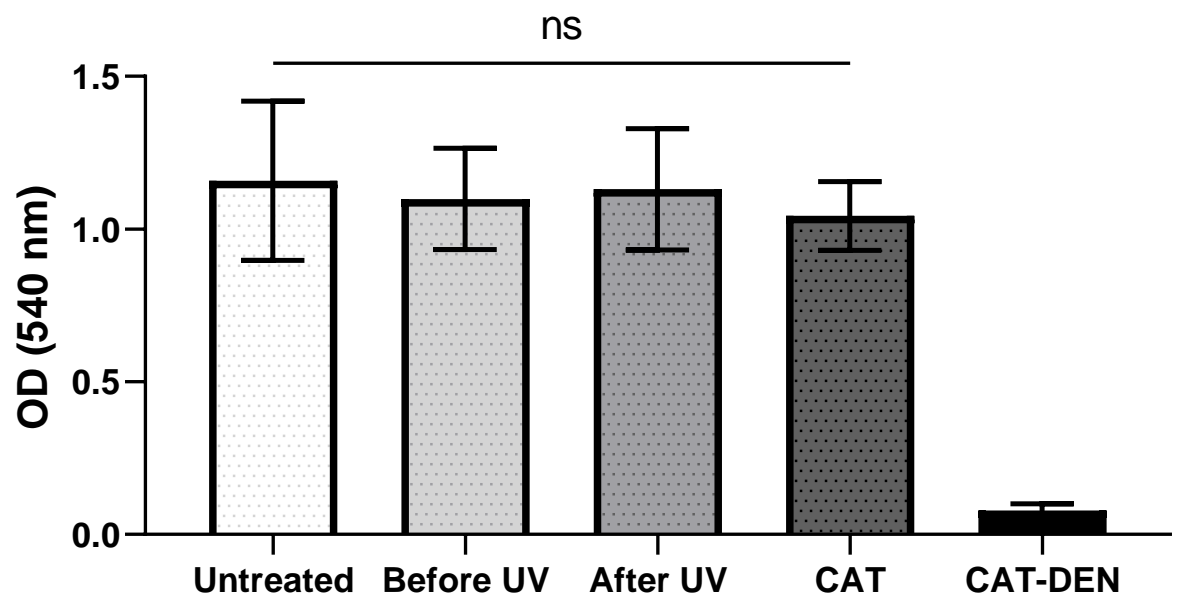

Figure 8: Catalase activity for untreated and PFPA-treated fibres before and after UV exposure. A freshly prepared catalase solution (CAT) and denatured catalase (CAT-DEN) were used as positive and negative controls, respectively. The data are presented as mean \pm S.D. $(n=3)$. Repeated measures one-way ANOVA with post hoc Tukey's test; statistical significance was not observed (ns).

The results of the catalase assay showed no change in the enzyme activity following attachment to the fibre surface. The optical density (OD) values for the fibre samples were the same as those for a freshly prepared solution containing a comparable amount of catalase, while the negative control - catalase heated to $95^{\circ} \mathrm{C}$ - showed markedly reduced OD, suggesting the loss

465 of enzymatic activity following denaturation at high temperature. Therefore, it can be concluded that the PFPA-NHS functionalisation does not negatively impact the biological activity of a protein being conjugated.

This work focused on the delivery of a model enzyme, catalase, but it is anticipated that the presented methodology can be extended to the conjugation of other pharmaceutically relevant proteins. In some applications, loading of protein cargo into the interior of a fibre may not be beneficial. For example,electrospun patches loaded with growth factors have been explored in wound healing (Lai et al., 2014; Wang et al., 2015). It is possible that depositing growth factors on the surface, rather than in the core, of electrospun patches could achieve a superior therapeutic performance in skin regenerative applications. Moreover, the PFPA-NHS 475 chemistry could be used in the design of dual-delivery scaffolds. For example, it may be possible to surface-functionalise fibres exhibiting a core-shell structure, where a therapeutic 
cargo is embedded within the core of a scaffold and is surrounded by a methanol-resistant polymer shell. Such dual-delivery systems could be attractive for applications in regenerative medicine, for instance in nerve regeneration (Xia and Lv, 2018).

\section{Conclusion}

This study demonstrates that electrospun PCL fibres can be successfully functionalised with proteins via perfluorophenyl azide chemistry. SEM, XPS and FTIR confirmed covalent modification of the scaffold by PFPA-NHS, and model fluorescent and protein molecules could be attached to the surface. The fibres were then functionalised with the enzyme catalase. PFPANHS-treated samples showed increased surface attachment over untreated controls. Catalase retained its enzymatic activity following attachment to the fibres and over $60 \%$ of the loading remained attached after six days of incubation. On the other hand, physically adsorbed catalase dissociated rapidly from the surface ( $~ 60 \%$ within the first 24 hours and $\sim 80 \%$ after six days), highlighting the importance of covalent conjugation via PFPA-NHS to extend a therapeutic effect. The PFPA-NHS functionalisation approach could be of great potential in applications where prolonged presentation of protein on the surface is required, for example in the design of growth factor-decorated implantable scaffolds in bone and cartilage tissue engineering (Chung and Park, 2007; Ma et al., 2005) or wound healing (Lai et al., 2014; Wang et al., 2015).

\section{Acknowledgements}

$495 \mathrm{KD}$ thanks the EPSRC for the award of a PhD studentship in the Centre for Doctoral Training in Advanced Therapeutics \& Nanomedicines (EP/L01646X/1). This project has received funding from the European Union's Horizon 2020 research and innovation programme under the Marie Skłodowska-Curie grant (agreement no 824007). We also thank Dr Pedro F. Costa of Biofabics for his support and mentorship of AM.

\section{6. References}

Angkawinitwong, U., 2018. Novel biopharmaceutical formulations from electrohydrodynamic atomisation. University College London.

Angkawinitwong, U., Awwad, S., Khaw, P.T., Brocchini, S., Williams, G.R., 2017. Electrospun formulations of bevacizumab for sustained release in the eye. Acta Biomater. 64, 126-136. https://doi.org/https://doi.org/10.1016/j.actbio.2017.10.015 
Bai, M.-Y., Liu, S.-Z., 2014. A simple and general method for preparing antibody-PEG-PLGA submicron particles using electrospray technique: An in vitro study of targeted delivery of cisplatin to ovarian cancer cells. Colloids Surfaces B Biointerfaces 117, 346-353. https://doi.org/https://doi.org/10.1016/j.colsurfb.2014.02.051

510 Bukhary, H., Williams, G.R., Orlu, M., 2020. Fabrication of Electrospun Levodopa-Carbidopa FixedDose Combinations. Adv. Fiber Mater. https://doi.org/10.1007/s42765-020-00031-1

Cao, H., Mchugh, K., Chew, S.Y., Anderson, J.M., 2010. The topographical effect of electrospun nanofibrous scaffolds on the in vivo and in vitro foreign body reaction. J. Biomed. Mater. Res. Part A 93A, 1151-1159. https://doi.org/10.1002/jbm.a.32609

515 Chen, G., Ito, Y., Imanishi, Y., 1997. Photo-immobilization of epidermal growth factor enhances its mitogenic effect by artificial juxtacrine signaling. Biochim. Biophys. Acta - Mol. Cell Res. 1358, 200-208. https://doi.org/https://doi.org/10.1016/S0167-4889(97)00065-7

Chen, X., Wang, X., Wang, S., Zhang, X., Yu, J., Wang, C., 2020. Mussel-inspired polydopamineassisted bromelain immobilization onto electrospun fibrous membrane for potential application as wound dressing. Mater. Sci. Eng https://doi.org/https://doi.org/10.1016/j.msec.2019.110624

Cheng, X., He, L., Xu, J., Fang, Q., Yang, L., Xue, Y., Wang, X., Tang, R., 2020. Oxygen-producing catalase-based prodrug nanoparticles overcoming resistance in hypoxia-mediated chemophotodynamic therapy. Acta Biomater. 112, 234-249. https://doi.org/https://doi.org/10.1016/j.actbio.2020.05.035

Chiu, Y.-J., Zhang, Z., Dziemidowicz, K., Nikoletopoulos, C.-G., Angkawinitwong, U., Chen, J.-T., Williams, R.G., 2020. The Effect of Solvent Vapor Annealing on Drug-Loaded Electrospun Polymer Fibers. Pharm. . https://doi.org/10.3390/pharmaceutics12020139

Chung, H.J., Park, T.G., 2007. Surface engineered and drug releasing pre-fabricated scaffolds for tissue engineering. Adv. Drug Deliv. https://doi.org/https://doi.org/10.1016/j.addr.2007.03.015

Dziemidowicz, K., Sang, Q., Wu, J., Zhang, Z., Zhou, F., Lagaron, J.M., Mo, X., Parker, G.J.M., Yu, D.-G., Zhu, L.-M., Williams, G.R., 2021. Electrospinning for healthcare: recent advancements. J. Mater. Chem. B. https://doi.org/10.1039/D0TB02124E

535 Fadel, T.R., Sharp, F.A., Vudattu, N., Ragheb, R., Garyu, J., Kim, D., Hong, E., Li, N., Haller, G.L., Pfefferle, L.D., Justesen, S., Harold, K.C., Fahmy, T.M., 2014. A carbon nanotube-polymer composite for T-cell therapy. Nat. Nanotechnol. 9, 639-647. https://doi.org/10.1038/nnano.2014.154

Guex, A.G., Hegemann, D., Giraud, M.N., Tevaearai, H.T., Popa, A.M., Rossi, R.M., Fortunato, G., 2014. Covalent immobilisation of VEGF on plasma-coated electrospun scaffolds for tissue engineering applications. Colloids Surfaces B Biointerfaces 123, 724-733. https://doi.org/https://doi.org/10.1016/j.colsurfb.2014.10.016

Johansson, L.H., Håkan Borg, L.A., 1988. A spectrophotometric method for determination of catalase activity in small tissue samples. Anal. Biochem. 174, 331-336. https://doi.org/https://doi.org/10.1016/0003-2697(88)90554-4

Labet, M., Thielemans, W., 2009. Synthesis of polycaprolactone: a review. Chem. Soc. Rev. 38, 34843504. https://doi.org/10.1039/B820162P

Lai, H.-J., Kuan, C.-H., Wu, H.-C., Tsai, J.-C., Chen, T.-M., Hsieh, D.-J., Wang, T.-W., 2014. Tailored design of electrospun composite nanofibers with staged release of multiple angiogenic growth factors for chronic wound healing. Acta Biomater. 10, 4156-4166. https://doi.org/https://doi.org/10.1016/j.actbio.2014.05.001 
Li, H., Sanchez-Vazquez, B., Trindade, R.P., Zou, Q., Mai, Y., Dou, L., Zhu, L.-M., Williams, G.R., 2019. Electrospun oral formulations for combined photo-chemotherapy of colon cancer. Colloids $\begin{array}{lcc}\text { Surfaces } & \text { B } & \text { Biointerfaces } \\ \text { https://doi.org/https://doi.org/10.1016/j.colsurfb.2019.110411 }\end{array}$

Li, L., Li, J., Kulkarni, A., Liu, S., 2013. Polyurethane (PU)-derived photoactive and copper-free clickable surface based on perfluorophenyl azide (PFPA) chemistry. J. Mater. Chem. B 1, 571582. https://doi.org/10.1039/C2TB00248E

Liu, Y., Xu, C., Gu, Y., Shen, X., Zhang, Y., Li, B., Chen, L., 2019. Polydopamine-modified poly(1lactic acid) nanofiber scaffolds immobilized with an osteogenic growth peptide for bone tissue regeneration. RSC Adv. 9, 11722-11736. https://doi.org/10.1039/C8RA08828D

Luetzow, K., Hommes-Schattmann, P.J., Neffe, A.T., Ahmad, B., Williams, G.R., Lendlein, A., 2019. Perfluorophenyl azide functionalization of electrospun poly(para-dioxanone). Polym. Adv. Technol. 30, 1165-1172. https://doi.org/10.1002/pat.4331

565 Ma, Z., Gao, C., Gong, Y., Shen, J., 2005. Cartilage tissue engineering PLLA scaffold with surface immobilized collagen and basic fibroblast growth factor. Biomaterials 26, 1253-1259. https://doi.org/https://doi.org/10.1016/j.biomaterials.2004.04.031

Moreira, A., Lawson, D., Onyekuru, L., Dziemidowicz, K., Angkawinitwong, U., Costa, P.F., Radacsi, N., Williams, G.R., 2020. Protein encapsulation by electrospinning and electrospraying. J. Control. Release. https://doi.org/https://doi.org/10.1016/j.jconrel.2020.10.046

Ogueri, K.S., Jafari, T., Escobar Ivirico, J.L., Laurencin, C.T., 2019. Polymeric Biomaterials for Scaffold-Based Bone Regenerative Engineering. Regen. Eng. Transl. Med. 5, 128-154. https://doi.org/10.1007/s40883-018-0072-0

Rim, N.G., Kim, S.J., Shin, Y.M., Jun, I., Lim, D.W., Park, J.H., Shin, H., 2012. Mussel-inspired surface modification of poly(l-lactide) electrospun fibers for modulation of osteogenic differentiation of human mesenchymal stem cells. Colloids Surfaces B Biointerfaces 91, 189-197. https://doi.org/https://doi.org/10.1016/j.colsurfb.2011.10.057

Rim, N.G., Shin, C.S., Shin, H., 2013. Current approaches to electrospun nanofibers for tissue engineering. Biomed. Mater. 8. https://doi.org/10.1088/1748-6041/8/1/014102

580 Wang, H., Chao, Y., Liu, J., Zhu, W., Wang, G., Xu, L., Liu, Z., 2018. Photosensitizer-crosslinked insitu polymerization on catalase for tumor hypoxia modulation \& enhanced photodynamic therapy. Biomaterials 181, 310-317. https://doi.org/https://doi.org/10.1016/j.biomaterials.2018.08.011

Wang, Z., Qian, Y., Li, L., Pan, L., Njunge, L.W., Dong, L., Yang, L., 2015. Evaluation of emulsion electrospun polycaprolactone/hyaluronan/epidermal growth factor nanofibrous scaffolds for wound healing. J. Biomater. Appl. 30, 686-698. https://doi.org/10.1177/0885328215586907

Xia, B., Lv, Y., 2018. Dual-delivery of VEGF and NGF by emulsion electrospun nanofibrous scaffold for peripheral nerve regeneration. Mater. Sci. Eng. C 82, 253-264. https://doi.org/https://doi.org/10.1016/j.msec.2017.08.030

Yan, M., Cai, S.X., Wybourne, M.N., Keana, J.F.W., 1994. N-Hydroxysuccinimide Ester Functionalized Perfluorophenyl Azides as Novel Photoactive Heterobifunctional Crosslinking Reagents. The Covalent Immobilization of Biomolecules to Polymer Surfaces. Bioconjug. Chem. 5, 151-157. https://doi.org/10.1021/bc00026a007

Yoshida, M., Langer, R., Lendlein, A., Lahann, J., 2006. From Advanced Biomedical Coatings to MultiFunctionalized Biomaterials. J. Macromol. Sci. Part C 46, 347-375. https://doi.org/10.1080/15583720600945394

Zhang, Y., Ouyang, H., Lim, C.T., Ramakrishna, S., Huang, Z.-M., 2005. Electrospinning of gelatin fibers and gelatin/PCL composite fibrous scaffolds. J. Biomed. Mater. Res. Part B Appl. Biomater. 
72B, 156-165. https://doi.org/10.1002/jbm.b.30128

Zorn, G., Liu, L.-H., Árnadóttir, L., Wang, H., Gamble, L.J., Castner, D.G., Yan, M., 2014. X-ray Photoelectron Spectroscopy Investigation of the Nitrogen Species in Photoactive Perfluorophenylazide-Modified Surfaces. J. Phys. Chem. C 118, 376-383. https://doi.org/10.1021/jp409338y 